Article - Engineering, Technology and Techniques

\title{
Viability Assays of PLLA Fibrous Membranes Produced by Rotary Jet Spinning for Application in Tissue Engineering
}

\section{Bárbara Etruri Ciocca ${ }^{{ }^{*}}$}

https://orcid.org/0000-0001-9402-2929

André Luiz Jardini Munhoz ${ }^{1}$

https:// orcid.org/0000-0002-9381-9335

\section{Guinea Brasil Camargo Cardoso ${ }^{1}$}

https:// orcid.org/0000-0002-5923-8289

\section{Ana Amélia Rodigues ${ }^{1}$}

https:// orcid.org/0000-0003-4407-8291

Ana Flávia Pattaro ${ }^{1}$

https:// orcid.org/0000-0001-8926-0703

Andreas Kaasi ${ }^{1}$

https:// orcid.org/0000-0002-2440-5593

\section{Rubens Maciel Filho'}

https:// orcid.org/0000-0001-6511-7283

${ }^{1}$ University of Campinas, National Institute of Biofabrication, SP, Brazil.

Received: 2017.12.05; Accepted: 2019.05.28.

* Correspondence: barbara_ciocca@hotmail.com; Tel.: +55-11-998766054

\section{HIGHLIGHTS}

- PLLA fibrous membranes were produced by rotary jet spinning.

- Membranes were subjected to preliminary in vitro assays to verify cytotoxicity.

- Direct cytotoxicity assays performed with fibroblastic and osteoblastic cells.

- PLLA membranes produced by rotary jet spinning showed promising results.

Abstract: Tissue engineering suggests different forms to reconstruct tissues and organs. One of the ways is through the use of polymeric biomaterials such as poly(L-lactic acid) (PLLA). PLLA is a recognized material in tissue engineering due to its characteristics as biocompatibility and bioresorbability. In this work PLLA fibrous membranes were produced 
by a simple technique known as rotary jet spinning. The rotary jet spinning consists of fibrous membranes production, with fibers of scale nano/micrometric, from a polymeric solution through the centrifugal force generated by the equipment. The membranes formed were subjected to preliminary in vitro assays to verify the cytotoxicity of the membranes made in contact with the cells. Direct cytotoxicity assays were performed through the MTT, AlamarBlue $\AA$ and Live/Dead $\AA$ tests, with fibroblastic and osteoblastic cells. The results obtained in this study showed that PLLA membranes produced by rotary jet spinning showed promising results in the 24-hours contact period of the cells with the PLLA fibrous membranes. The information presented in this preliminary study provides criteria to be taken in the future procedures that will be performed with the biomaterial produced, aiming at its improvement.

Keywords: Tissue engineering, Poly(L-lactic acid), Biomaterial, Rotary jet spinning, in vitro assay.

\section{INTRODUCTION}

The tissue engineering is a very promising new field that aims the construction and development of new tools for medicine, aiming the regeneration of tissues in search of the improvement of the quality of life of the population [1]. It is an interdisciplinary area where the biological, medical and scientific areas are interconnected throughout the process (manufacturing, characterization and application of the materials under development). Such areas focus on the goal of developing artificial substrates that mimic the environment in which the cells reside; such substrates are known as biomaterials. Biomaterials must be biocompatible to be implanted in human body, and their properties will depend directly on the region which it will be applied [2, 3].

In recent years there has been a considerable advance in the area that has been stimulated due to the increase of life expectancy of world population, high rate of traffic accidents, accidents at work and urban violence. Another factor that stimulates the development of the area is the high cost of prostheses and medical devices for patients.

The development of new biomaterials, new methods of manufacturing or perfecting existing ones is crucial for the development of tissue engineering [4]. There is a wide range of materials being used as biomaterials, such as metals, ceramics, composites and polymers. Among the cited materials, the most versatile and widely used in tissue engineering are polymers, due to their production characteristics, wide range of options and applications in the market.

Several polymers have been used for this application, among them a widely used polymer already established in the literature, is poly(L-lactic acid) (PLLA). PLLA is a well-established polymer in the medical field due to its characteristics as bioresorbability and biocompatibility, presenting favorable aspects of processability, formulation flexibility, excellent structural properties and low cost when compared to the conventional materials currently available in the implant industry $[5,6]$.

PLLA is a thermoplastic polyester made with lactic acid (mixed function organic compound - carboxylic acid and alcohol), which makes it bioresorbable. It is considered a biopolymer due to its characteristics, therefore its applications are very broad in tissue engineering. In contact with the human body, PLLA is hydrolyzed to lactic acid, which under aerobic conditions is metabolized in water and carbon dioxide, and is ultimately excreted by the body. One disadvantage of PLLA is its brittleness and rigidity, which limits the areas of application [6, 7].

The use of polymeric microfibers in the medical field has grown considerably due to its diverse possibilities of application as artificial skin, bandages for wound regeneration, balloon angioplasty, intragastric balloons, scaffolds, neural connections, among others. One method of producing fibers in micrometric scale, simple and easy to handle is rotary jet 
spinning (RJS). This method can be described as a process where a polymer solution is exposed to a high speed of rotation, which will form a long polymeric jet that extends before its solidification [8].

For the development of medical devices for tissue engineering, in vitro tests are necessary, where they seek to develop systems of cell culture that closely resemble the conditions of the human body, and it is necessary to control several factors that influence the cell development such as temperature, growth factors, physical stimuli, among others. The cells behave according to the characteristics of the matrix such as porosity, pore geometry, chemical composition and surface topography, in this way the choice of the cell type to be worked depends on the properties of the matrix [9].

There are several types of tests in the cell culture to verify toxicity, apoptosis, genotoxicity, chromosomal anomalies, uncontrolled cell proliferation, among several other tests. The main tests of cell culture are performed initially with the fibroblastic cell line, since the connective tissue is the most abundant tissue of the human body. Fibroblastic cells are connective tissue immature cells responsible for healing process and formation of the extracellular matrix. Another widely studied tissue of the human body is bone tissue, since there are a large number of accidents involving fractures and the price of prostheses is high. Thus, the study of bone tissue immature cells, the osteoblastic cells, is extremely important for the development of new biomaterials for tissue engineering, where we seek less wear and tear for the patient as well as for the public system [10].

In this work the focus will be given to tests that evaluate the cell viability through biological responses obtained by in vitro tests such as MTT, AlamarBlue ${ }^{\circledR}$ and Live/Dead® with two types of cell lines, osteoblastic cells and fibroblastic cells, for the validation of cytotoxicity of PLLA microfibers and the possibility of using them as biomaterial for tissue engineering.

\section{MATERIAL AND METHODS}

The PLLA used in this work was synthesized and provided by the research group of the National Biofabrication Institute (INCT-Biofabris / UNICAMP) [11].

\section{Preparation of PLLA Solution for RJS}

The PLLA solution was prepared by dissolving the polymer in chloroform [ $\mathrm{CHCl} 3,99 \%]$ from Synth (Brazil) at a concentration of $0.2 \% \mathrm{~m} / \mathrm{v}$ at room temperature. The final solution was prepared with a total volume of $15 \mathrm{~mL}$.

\section{Preparation of Membranes by RJS}

The RJS equipment used in this work was designed and built by the Laboratory of biomaterials and biomechanics (LABIOMEC/UNICAMP), where it is found. The equipment consists of a reservoir with four small holes in the wall, a manifold and a base coupled to the engine. The collector was covered with aluminum foil to facilitate removal of the fibers after the process. The speed used was stabilized at approximately 6,500 RPM, the PLLA solution was continuously being deposited with a syringe in an orifice above the reservoir in order to maintain the continuous flow, and the entire process was performed at room temperature.

\section{Scanning Electron Microscopy (SEM)}

Morphological surface of PLLA membrane was analyzed by Scanning Electron Microscopy (SEM) using in the LEO - scanning electron microscope (Oxford, Leo 440i, Cambridge, England), with a voltage of $20 \mathrm{kV}$ and a current of $100 \mathrm{pA}$. In order to perform this analysis, the sample had to go through a metallic coating process with gold on a metallizer (SputterCoater EMITECH, K450, Kent, UK), in the Laboratory of Biomass 
Characterization, Analytical Resources and Calibration (LRAC/UNICAMP) following the method described in detail elsewhere 11.

\section{Cell Culture}

To be possible to carry out the viability assays, the membrane went through an ethylene oxide sterilization supplied by ACECIL (Central Sterilization Trade and Industry Ltda, Campinas). Thereafter, the membrane was cut with scissors into $0.5 \mathrm{~cm} \times 1 \mathrm{~cm}$ squares, to be possible to be placed in the wells. For the positive and negative toxicity controls were used the specific medium of each cells (VERO - DMEM-LG and M3CT3-E1 - MEM-ALFA) supplemented with $10 \%$ phenol as a positive toxicity control (PCT), and supplemented with $10 \%$ fetal bovine serum (FBS) and $1 \%$ penicillin and streptomycin (PS) was used as negative toxicity control (NCT).

\section{Fibroblastic Cells}

VERO cell culture (African green monkey kidney fibroblasts) used in this study was provided by the Adolfo Lutz Institute (São Paulo, Brazil). Cells were cultured with Dulbecco's modified Eagle's medium with low glucose concentration (DMEM-LG), and supplemented with $10 \%$ FBS and $1 \%$ PS, all provided by Gibco. Cells were cultured in 96-well culture plates (Corning Costar Corporation) and maintained for 24 hours at $37^{\circ} \mathrm{C}$ in an incubator (Sanyo Scientific, USA) with $5 \% \mathrm{CO}_{2}$ atmosphere and $95 \%$ ambient air for 24 hours before the assays. After that, the RJS PLLA membranes were added to the plate and incubated for 24 hours. To determine and realize the direct cytotoxicity assays of RJS PLLA, the PLLA membranes were removed from the wells and the concentration of the VERO cells at the bottom of the plate was evaluated at $1 \times 106$ cells $/ \mathrm{mL}$.

\section{Osteoblastic Cells}

The M3CT3-E1 osteoblastic cell line used in this work was purchased from the ATCC. Cells were cultured with Eagle's minimal essential culture media (MEM-ALFA, Vitrocell), supplemented with $10 \%$ FBS and $1 \%$ PS, all provided by Gibco. Cells were cultured in 96-well culture plates (Corning Costar Corporation) and maintained for 24 hours at $37^{\circ} \mathrm{C}$ in an incubator (Sanyo Scientific, USA) with $5 \% \mathrm{CO}_{2}$ atmosphere and $95 \%$ ambient air for 24 hours before the assays. After that, the RJS PLLA membranes were added to the plate and incubated for 24 hours. To determine and realize the direct cytotoxicity assays of RJS PLLA, the PLLA membranes were removed from the plates and the concentration of the M3CT3-E1 cells at the bottom of the plate was evaluated at $1 \times 106$ cells $/ \mathrm{mL}$.

\section{Direct Cytotoxicity Assay By MTT}

VERO and M3CT3-E1 cells were incubated with $200 \mu \mathrm{l}$ of MTT cell culture media dissolved for 4 hours. The optical density of the viable cells were accessed by absorbance reading on Microplate Reader (Microplate Reader F5, Molecular Probes) at wavelength 595 $\mathrm{nm}$.

\section{Direct Cytotoxicity Assay By Alamarblue ${ }^{\circledR}$}

The AlamarBlue ${ }^{\circledR}$ assay was performed as a form of validation of the MTT result of direct cytotoxicity, since AlamarBlue ${ }^{\circledR}$ is more sensitive than MTT 12. Both cells culture media were withdrawn and $50 \mu \mathrm{L}$ of the AlamarBlue ${ }^{\circledR}$ reagent solution was added to the wells following manufacturer's recommendations. The presence of viable cells was detected 
by fluorescence filters at $460 \mathrm{~nm}$ (emission) and $630 \mathrm{~nm}$ (excitation) in Microplate Reader (Microplate Reader F5, Molecular Probes).

\section{Live/Dead@ In Vitro Cell Viability Assay}

In order to obtain images by fluorescence microscopy, M3CT3-E1 and VERO cells were labeled with a specific kit (Live/Dead® Viability cytotoxicity) according to the recommendations of the manufacturer. Cells were incubated in solution containing $2 \mu \mathrm{M}$ propidium iodide to mark the viable cells (excitation: 490-638 nm) and $2 \mu \mathrm{M}$ AM calcein to mark the non-viable cells (excitation: $480-500 \mathrm{~nm}$ ) for 30 minutes at $37^{\circ} \mathrm{C}$ for labeling viable and non-viable cells, respectively. After incubation period the cells were observed under a microscope with fluorescence filters (Nikon E800) and the images captured with specific software (Image Pro-Plus software). Two identical images were taken from the same bottom region of the wells of the plates with filters with emission and excitation lengths corresponding to the fluorochromes present in the kit. These images were superimposed on microscopy imaging software (ImageJ®).

\section{Statistical Analysis}

The results of the AlamarBlue $\AA$ and MTT tests were submitted to a normality test (Shapiro-Wilk) followed by analysis of variance (ANOVA) and Tukey's test. Data are presented as mean \pm standard deviation, and the significance level adopted was 0.05 . Statistical analyzes were performed using the PAST software.

\section{RESULTS}

\section{The Morphological Surface Analysis}

The obtained PLLA membrane through rotary jet spinning process is shown in Figure 1, where is possible to note uniform fibers without defects like beads and pores along them. In this way, it is possible to confirm the success of rotary jet spinning process to obtain fibers.

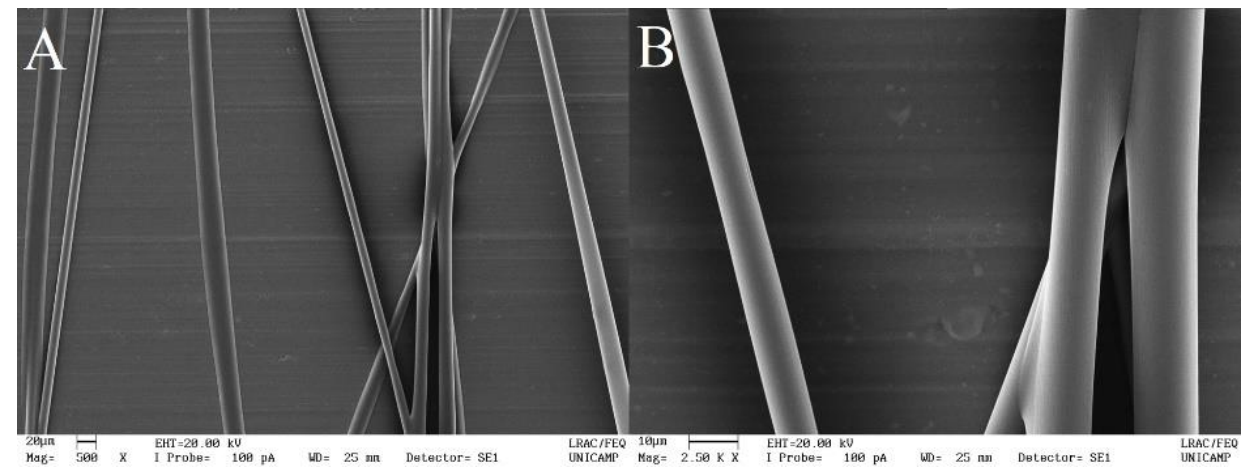

Figure 1. Scanning electron micrographs of PLLA fibers obtained by rotary jet spinning process at magnification of $500 \times(a)$ and $2500 x(b)$.

\section{Direct Cytotoxicity by MTT}

The cytotoxicity test was performed to assess whether PLLA membranes exhibited toxic behavior to cells. VERO and M3CT3-E1 cells were contacted with the PLLA membranes for 24 hours, and then the MTT assay was performed. Results obtained from viable cells in contact with PLLA and their controls (PCT and NCT) are shown in Figure 2. 


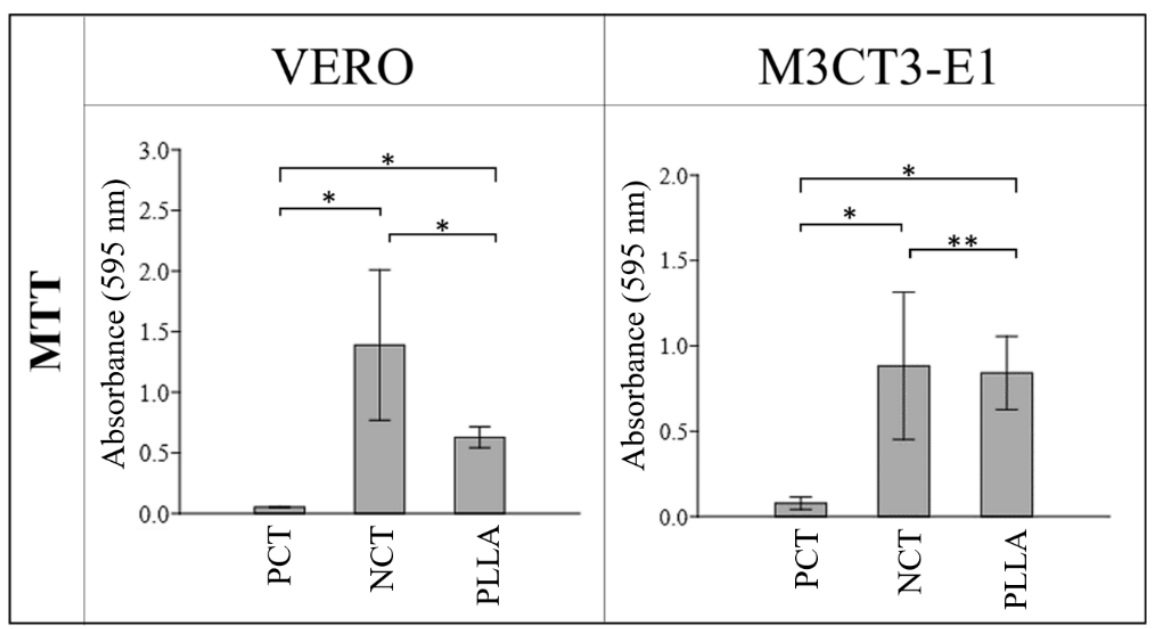

Figure 2. Cell viability by MTT assay in terms of mean optical density of M3CT3-E1 and VERO cells in contact with PLLA compared to positive (PCT) and negative (NCT) toxicity controls. Values are mean with standard deviation, statistics: one-way ANOVA followed by Tukey's test in which, ${ }^{*}: p<0.05$, and ${ }^{* *}: p>0.05$.

\section{Direct Cytotoxicity by AlamarBlue®}

As an alternative to validate the citotoxicity results of the PLLA membranes obtained in the MTT assay, the AlamarBlue ${ }^{\circledR}(A B)$ assay was performed after 24 hours of PLLA contact with the VERO and M3CT3-E1 cells, and their PCT and NCT controls. The results obtained from the viable cells are shown in Figure 3.

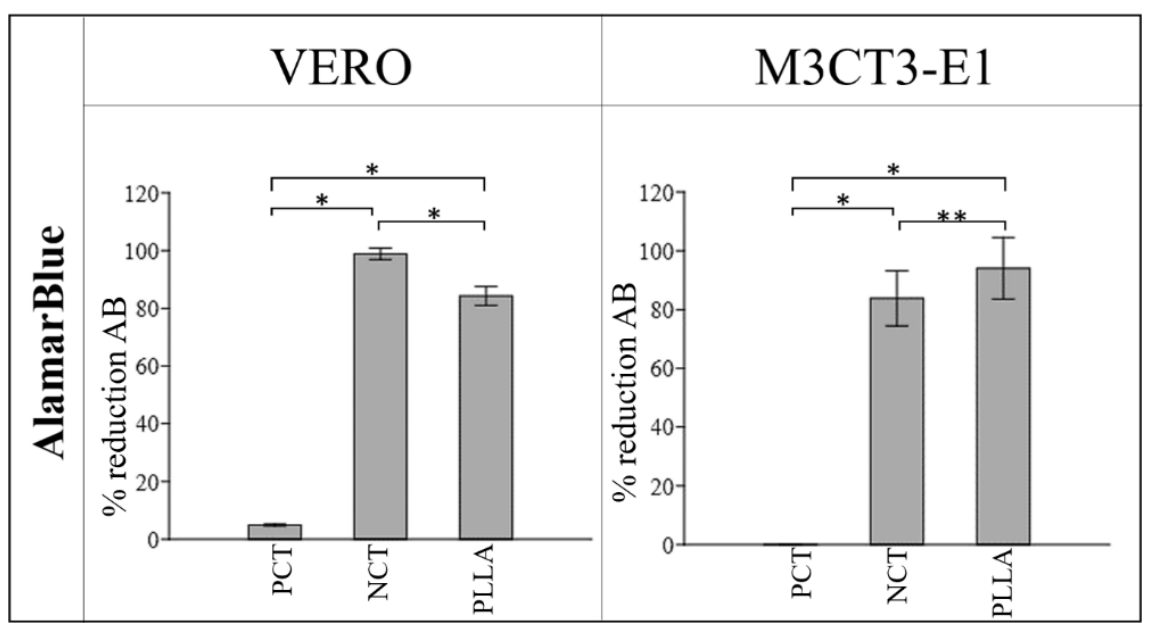

Figure 3. Cell viability by AlamarBlue $\AA$ assay in terms of mean optical density of M3CT3-E1 and VERO cells in contact with PLLA compared to positive (PCT) and negative (NCT) toxicity controls. Values are mean with standard deviation, statistics: one-way ANOVA followed by Tukey's test in which, ${ }^{*}$ : $p<0.05$, and ${ }^{* *}: p>0.05$.

\section{Direct Cytotoxicity by Live/Dead®}

The toxicity of PLLA and cell viability after 24 hours of contact was determined by the Live/Dead® assay kit. Viable cells (green-labeled) and dead cells (red-labeled) were visualized by fluorescence microscopy as shown in Figure 4. After 24 hours contact of membranes with cultures, PLLA was removed and the images obtained In Figure 3 are of the cells adhered to the bottom of the plate. 
Figure 4 shows that in 24 hours contact of RJS PLLA with the culture, a predominance of living cells (green) was found for both VERO cells and M3CT3-E1 cells. These results were further confirmed with the MTT assays (Figure 2) and AlamarBlue ${ }^{\circledR}$ (Figure 3 ). The results suggest that PLLA did not compromise cell viability and transport of nutrients and oxygen to cells, since the PLLA images in Figure 4 resemble NCT images.

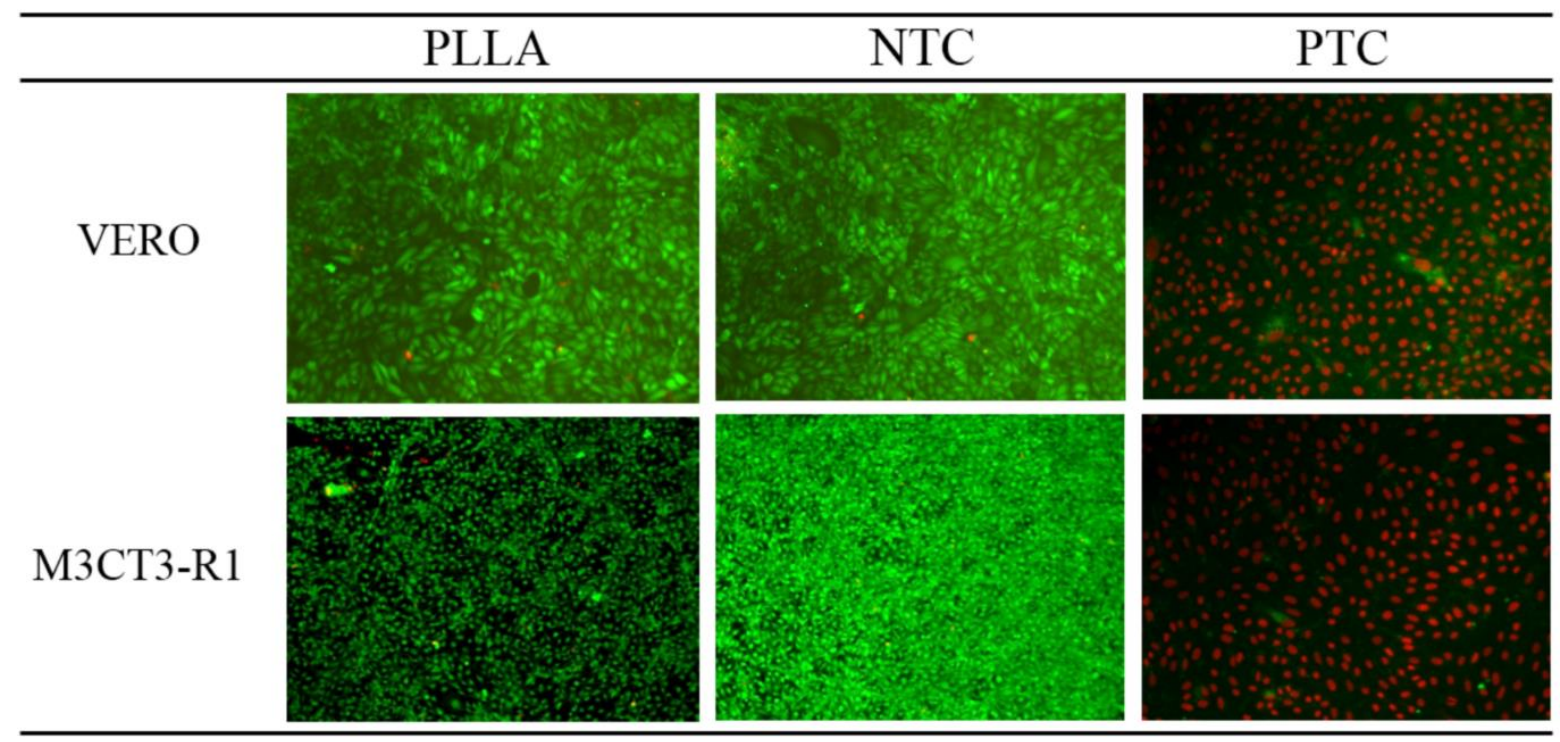

Figure 4. Live/Dead assay of VERO and M3CT3-E1 cells after 24 hours of contact with PLLA, and negative (NCT) and positive (PTC) toxicity controls. Images from the bottom of the well culture plates.

\section{Statistical Analyzes}

The results obtained in the MTT and AlamarBlue ${ }^{\circledR}$ assays of the VERO and M3CT3-E1 cells were submitted to the Shapiro-Wilk test to verify the normality of the data with $95 \%$ confidence. All tests were within normal range with $p$ values $>0.05$. Once the normality of the data was confirmed, it was possible to perform analysis of variance (ANOVA) and Tukey's test, where values of $p<0.05$ and valuesof $Q s$ higher than the value of $Q$ critical (3.95) are considered significantly different. The values obtained for the Tukey test are shown in Table 1. It can be noted that all PCTXNCT and PCTXPLLA interactions for VERO and M3CT3-E1 cells, and the NCTXPLLA interaction of VERO cells were significant, indicating that there is a difference between the behavior of the cells with their controls.

Table 1. Values obtained in the Tukey test.

\begin{tabular}{|c|c|c|c|c|c|}
\hline & & & PCT $x$ NCT & PCT x PLLA & NCT x PLLA \\
\hline \multirow{4}{*}{ M3CT3-E1 } & \multirow{2}{*}{ MTT } & $\mathrm{p}$ (value) & 0.000229 & 0.000255 & 0.911200 \\
\hline & & Qs & 11.3 & 10.7 & 0.6 \\
\hline & \multirow{2}{*}{$\mathbf{A B}$} & $\mathrm{p}$ (value) & 0.000227 & 0.000227 & 0.052270 \\
\hline & & Qs & 35.0 & 39.3 & 4.3 \\
\hline \multirow{4}{*}{ VERO } & \multirow{2}{*}{ MTT } & $\mathrm{p}$ (value) & 0.000183 & 0.000183 & 0.000183 \\
\hline & & Qs & 166.7 & 140.7 & 26.0 \\
\hline & \multirow{2}{*}{$\mathbf{A B}$} & $\mathrm{p}$ (value) & 0.000185 & 0.0004432 & 0.000797 \\
\hline & & Qs & 14.5 & 6.3 & 8.3 \\
\hline
\end{tabular}




\section{DISCUSSION}

It was possible to evaluate in this work the morphological structure of PLLA fibrous membranes produced by the rotary jet spinning technique and its potential for cell viability.

Rotary jet spinning is known to be a relatively new process where polymeric membranes and fibers, ranging to micro from nano-scales, can be produced through a high speed of rotation in which a polymer solution is exposed [13]. The use of RJS technique shows a great advantage when compared to the electrospinning, the most used nowadays, since the use of electric field and conductive electrical solution is not necessary, making RJS an attractive and low cost process [14].

When analyzing the obtained PLLA fibers in SEM (Figure 1) is possible to note the formation of uniform and no presence of beads and pores along them. Comparing the fibers obtained in this work by RJS with the fibers obtained in other work in literature also using RJS [14], the results are significantly different showing beads and pores along the fibers, and the production of nanofibers while this work presented homogenous PLLA microfibers. The formation of PLLA fibers without defects demonstrates that the process occurred ideally, with a good viscosity and concentration maintaining the solution physical properties during the process [16].

The success of a fibrous membrane is directly associated with cellular response. The fibers present in the membrane must mimic the structure of the original tissue and cause no adverse response. In this way, this work presented three cell viability assays (MTT, AlamarBlue $\AA$ and Live/Dead $($ ) ) as a way to evaluate the toxicity of the manufactured PLLA membranes in contact for 24 hours with two different types of cell lines (Vero and M3CT3-E1) to investigate the initial behavior of cells.

Through the viability assays like MTT and AB, it was possible to notice (Figures 2 and 3 ) a low response for positive toxicity control as expected, once the cells are dead in these controls and a similar behavior between the cells in contact with PLLA and the cells in the negative toxicity control. However, the statistical analysis showed similarity only between the group of PLLA and negative toxicity control for the M3CT3-E1 ( $p>0.05)$, all other interaction groups results were statistically different $(p<0.05)$. This similarity can be due to the fact that the standard deviations of these groups are intersecting, and to the fact that AlamarBlue ${ }^{\circledR}$ assay is more sensitive and accurate than MTT assay [12]. The results allied to one-way ANOVA and Tukey's test were promising, and it was possible to conclude that there was no toxicity of PLLA membranes produced by RJS technique when in contact with both cells lines.

As a way of qualitatively evaluating cell viability in contact with PLLA the Live/Dead® assay was performed with Vero and M3CT3-E1 cell lines (Figure 4). The results obtained in this assay shows an intense red fluorescence for positive toxicity control confirming the death of the cells present for both cell lines, and an intense and similar green fluorescence for negative toxicity control and for the cells that were in contact with the membranes (PLLA). These results can be compared with literature [17], where the results for 24 hours of contact of the cells in controls and in contact with material have a similar behavior. In both cases, the materials and the negative controls are intense green colored indicating live cells and the positive controls are red colored what indicates cell death.

Thus, with the results of this work is possible to affirm that RJS process is a promising technique to obtain fibrous membranes from PLLA, and the parameters used were ideal to fibers without defects. The PLLA membranes do not presented a toxic behavior in contact with two cell lines, indicating good properties to be used in tissue engineering, once it do not interfere in cellular viability.

\section{CONCLUSION}

This study highlights the production of PLLA membranes through RJS and the evaluation of the cytotoxicity of these membranes with two cell types, aiming to study in the future its potential for applications in tissue engineering. 
PLLA fibrous membranes were successfully produced by the RJS technique, and demonstrated a non-toxic behavior, not generating a negative response when exposed in contact with fibroblastic and osteoblastic cells. It was observed that the fibrous membranes obtained were able to maintain the function of both cell types, without cytotoxicity to the cells.

Although the present results are preliminary it is possible to note that biological assays, and statistical analyzes performed with two cell types have shown positive results. This work supports further investigation of PLLA fibrous membranes through the RJP technique for innumerable applications in tissue engineering, and further biological studies.

Funding: This research was funded by CAPES.

Acknowledgments: The authors are grateful for the support provided by CAPES, FAPESP (2008/57680-3) and the National Institute of Biofabrication (INCT-Biofabris).

Conflicts of Interest: The authors declare no conflict of interest.

\section{REFERENCES}

1. Ghanavati, Z.; Neisi, N.; Bayati, V.; Makvandi, M. The influence of substrate topography and biomaterial substance on skin wound healing. Anat. Cell Biol. 2015, 48, 251-257. doi:10.5115/acb.2015.48.4.251.

2. Diao, H.J.; Wang, K.; Long, H.Y.; Wang, M.; Chew, S.Y. Highly Fluorescent and Photostable Polymeric Nanofibers as Scaffolds for Cell Interfacing and Long-Term Tracking. Adv. Healthc. Mater. 2016, 5, 529-533. doi:10.1002/adhm.201500693.

3. Mahoney, C.; Conklin, D.; Waterman, J.; Sankar, J.; Bhattarai, N. Electrospun nanofibers of poly(E-caprolactone)/depolymerized chitosan for respiratory tissue engineering applications. J. Biomater. Sci. Polym. Ed. 2016, 27, 611-625. doi:10.1080/09205063.2016.1144454.

4. Joshi, M.K.; Pant, H.R.; Tiwari, A.P.; Maharjan, B.; Liao, N.; Kim, H.J.; et al. Three-dimensional cellulose sponge: Fabrication, characterization, biomimetic mineralization, and in vitro cell infiltration. Carbohydr. Polym. 2016, 136, 154-162. doi:10.1016/j.carbpol.2015.09.018.

5. Zhang, Y.; Chwee, T.L.; Ramakrishna, S.; Huang, Z.M. Recent development of polymer nanofibers for biomedical and biotechnological applications. J. Mater. Sci. Mater. Med. 2005, 16, 933-946. doi:10.1007/s10856-005-4428-x.

6. Pongtanayut, K.; Thongpin, C.; Santawitee, O. The Effect of Rubber on Morphology, Thermal Properties and Mechanical Properties of PLA/NR and PLA/ENR Blends. Energy Procedia. 2013, 34, 888-897. doi:10.1016/j.egypro.2013.06.826.

7. Nair, L.S.; Laurencin, C.T. Biodegradable polymers as biomaterials. Prog. Polym. Sci. 2007, 32, 762-798. doi:10.1016/j.progpolymsci.2007.05.017.

8. Badrossamay, M.R.; Mcllwee, H.A.; Goss, J.A.; Parker, K.K. Nanofiber assembly by rotary jet-spinning. Nano Lett. 2010, 10, 2257-2261. doi:10.1021/nl101355x.

9. Aparecida, A.H.; Fook, M.V.L.; Guastaldi, A.C. Desenvolvimento de Scaffold Poroso Bioativo de Peuapm para Utilização como Biomaterial para Reposição e Regeneração Óssea. $10^{\circ}$ Congresso Brasileiro de Polímeros; 2008; Foz do Iguaçu. An. 10 Congr. Bras. Polim; 2009, pp.1-6.

10. Junqueira, L.C.U.; Carneiro, J. Histologia básica. 12 ed., Rio de Janeiro: Guanabara Koogan Ltda; 2013.

11. Pattaro, A.F. Síntese, Caracterização e Processamento de Polímeros Biorreabsorvíveis para uso na Engenharia de Tecidos (Tissue Engineering) [dissertation]. Campinas, Brazil. School of Chem. Eng. University of Campinas; 2016.

12. Hamid, R.; Rotshteyn, Y.; Rabadi, L.; Parikh, R.; Bullock, P. Comparison of alamar blue and MTT assays for high through-put screening. Toxicol. Vitr. 2004, 18, 703-710. doi:10.1016/j.tiv.2004.03.012. 
13. Badrossamay, M.R; Balachandran, K.; Capulli, A.K.; Golecki, H.M.; Agarwal, A.; Goss, J.A.; Kim, H.; Shin, K.; Parker, K.K. Engineering hybrid polymer-protein super-aligned nanofibers via rotary jet spinning, Biomat. 2014, 35, 3188-3197.

14. Vida, T.A.; Motta, A.C.; Santos Jr., A.R.; Cardoso, G.B.C.; Brito, C.C.; Zavaglia, C.A.C. Fibrous PCL/PLLA Scaffolds Obtained by Rotary Jet Spinning and Electrospinning. Mater. Res. 2017, 20, 910-916. doi: http://dx.doi.org/10.1590/1980-5373-MR-2016-0969.

15. Jaiswal, A. Nanofibrous Scaffolds for Tissue Engineering Applications. Braz. Arch. Biol. Technol. 2016, 59, e16150644. doi: http://dx.doi.org/10.1590/1678-4324-2016150644.

16. Perea, G.N.R. Eletrofiação de nanocompósito de poli(Lácido lático) com hidroxiapatita para regeneração óssea [disseration]. Campinas, Brazil. School of Mech. Eng. University of Campinas; 2011.

17. Linan, L.Z.; Lima, N.M.N.; Benatti, C.; Xavier, M.; Rodrigues, A.A.; Manenti, F.; et al. Cytotoxicity Assessment of a Poly(methyl methacrylate) Synthesized for the Direct Fabrication of Bone Tissues. Braz. Arch. Biol. Technol. 2018, 61, e18160526. doi:http://dx.doi.org/10.1590/1678-4324-2018160526.

2018 by the authors. Submitted for possible open access publication under the terms and conditions of the Creative Commons Attribution (CC BY NC) license (http://creativecommons.org/licenses/by-nc/4.0/). 